\title{
Pelatihan Peningkatan Self-Esteem pada Mahasiswa Universitas Indonesia yang Mengalami Distres Psikologis
}

\author{
(Self-Esteem Building Training for University of Indonesia Students \\ Experiencing Psychological Distress)
}

\author{
BONA S. H. HUTAHAEAN ${ }^{1}$, NATHANAEL E. J. SUMAMPOUW
}

Fakultas Psikologi, Universitas Indonesia

Email: bonasardo@ui.ac.id ${ }^{1}$

\begin{abstract}
Abstrak: Mahasiswa dengan tingkat self-esteem yang tinggi cenderung memiliki penyesuaian yang baik di perkuliahan. Mereka akan memiliki kemampuan untuk menangani masalah kuliah dan secara otomatis mengurangi distres psikologis mereka. Penelitian ini menggunakan metode eksperimental kuasi yang dilakukan untuk mengetahui peningkatan self-esteem pada mahasiswa yang mengalami distres psikologi. Partisipan penelitian ini adalah 8 mahasiswa S1 Universitas Indonesia yang berusia 18-23 tahun dengan tingkat self-esteem di bawah nilai 29 yang diukur dengan Rosenberg self-esteem scale (RSES), dan memiliki tingkat distres psikologi di atas nilai 1.75 yang diukur dengan HSCL-25. Partisipan terlibat dalam intervensi peningkatan self-esteem yang terdiri dari 5 sesi utama selama dua hari berturut-turut (sekitar 6 jam dalam sehari). Empat minggu setelah hari kedua pelatihan, tingkat self-esteem dan distres psikologis responden diukur. Hasil pengukuran sebelum dan sesudah intervensi pelatihan menunjukkan bahwa skor mean self-esteem peserta mengalami peningkatan dan skor mean distres psikologis mengalami penurunan. Hasil uji Wilcoxon juga menunjukkan perubahan yang signifikan pada kedua variabel (Z RSES $=-2.246$; Z HSCL-25 $=-2.366 ; \mathrm{p}<.05$ ). Penelitian ini menunjukkan bahwa intervensi pelatihan efektif dalam meningkatkan self-esteem dan menurunkan distres psikologis bagi mahasiswa S1 Universitas Indonesia. Peserta juga berkomentar bahwa mereka memperoleh pengetahuan baru mengenai self-esteem dan keterampilan baru untuk berkomunikasi secara asertif dan berpikir positif.
\end{abstract}

Kata kunci: mahasiswa sarjana; self-esteem; distres psikologis; intervensi pelatihan

\begin{abstract}
Undergraduate students with high levels of self-esteem tend to have good adjustments in lectures. They will have the ability to deal with college problems and automatically reduce their psychological distress. This study used a quasi experimental method which is conducted to determine the increase of self-esteem in students who experience psychological distress. Participants of this study were 8 undergraduate students from Universitas Indonesia aged 18-23 years with a level of selfesteem below the value of 29 as measured by Rosenberg self-esteem scale (RSES), and had a level of psychological distress above the value of 1.75 as measured by HSCL-25. Participants were involved in the intervention of increasing self-esteem consisting of 5 main sessions for two consecutive days (about 6 hours a day). Four weeks after the second day of training, the participant's level of selfesteem and psychological distress were measured. The result of pre and posttest intervention showed that the participant's mean score of self-esteem increased and the mean score of psychological distress decreased. The result of Wilcoxon test also showed a significant change in both variables $(Z$ $R S E S=-2.246 ; Z$ HSCL-25 = -2.366; $p<.05)$. This study shows that training intervention is effective in increasing the level of self-esteem and reducing the level of psychological distress for undergraduate students at Universitas Indonesia. Participants also commented that they gained new knowledge about self-esteem and new skills to communicate assertively and think positively.
\end{abstract}

Key words: undergraduate students; self-esteem; psychological distress; training intervention 


\section{PENDAHULUAN}

Mahasiswa yang umumnya berusia 18 hingga 25 tahun berada pada masa transisi perkembangan dari remaja menuju dewasa yang sangat berbeda dari tahap perkembangan yang lain (Arnett, 2000). Papalia dan Martorell (2014), menjelaskan bahwa masa transisi tersebut meliputi persiapan-persiapan seperti, perpindahan menuju struktur sekolah yang lebih besar dan impersonal, interaksi dengan peer group yang berasal dari latar belakang etnik dan kultur yang lebih variatif, fokus yang lebih meningkat terhadap performa akademik, pencapaian prestasi, serta penilaian orang lain. Adanya tekanan untuk sukses di dunia perkuliahan, mendapatkan pekerjaan yang layak, dan menghasilkan pendapatan yang memadai, merupakan beberapa hal yang dapat menjadi sumber stres atau stressor di kalangan mahasiswa (Hales, 2009; Santrock, 2013). Adanya berbagai tuntutan dan stressor tersebut, tidak heran jika masa transisi dari siswa SMA menuju mahasiswa tahun pertama dapat menjadi suatu hal yang sangat menantang (Hales, 2009), sehingga dapat mengakibatkan munculnya distres psikologis yang turut memberikan pengaruh negatif dalam kehidupannya.

Distres psikologis ialah penderitaan emosional yang dialami oleh individu (Mirowsky \& Ross, 2003). Stallman (2010), menjelaskan bahwa distres psikologis yang terlalu tinggi dapat mengganggu kinerja individu yang mengalaminya (performance impairment/dissability). Lebih lanjut dijelaskan pula bahwa tingkat distres psikologis yang tinggi secara signifikan berkorelasi negatif dengan performa akademis pada mahasiswa (Stallman, 2010). Artinya, mahasiswa yang memiliki tingkat distres psikologis yang tinggi cenderung diasosiasikan dengan performa akademis yang buruk.

Kemunculan distres psikologis yang paling sering terjadi pada mahasiswa tahun pertama ialah top-dog phenomenon, yaitu situasi perpindahan dari posisi sebagai senior yang lebih berkuasa dan lebih tua di SMA menjadi posisi junior yang lebih muda dan kurang berkuasa di universitas (Santrock, 2013). Fenomena tersebut membuat mahasiswa baru merasa kewalahan secara berkala, hingga dapat mengarah pada peningkatan stres dan depresi (Santrock, 2013). Oleh karena itu, mahasiswa baru tentu harus mampu menyesuaikan diri dengan posisinya sebagai junior di kampus. Ketika mahasiswa tidak mampu melakukan penyesuaian diri secara baik, ia cenderung akan memperoleh nilai yang tidak memuaskan, menampilkan performa yang tidak optimal pada beberapa mata kuliah atau bahkan gagal untuk lulus di mata kuliah tertentu, serta menunjukkan kecenderungan untuk droppedout atau putus studi sebelum pendidikannya tamat (Verger dkk., 2009) Sebaliknya, mahasiswa yang mampu menyesuaikan diri cenderung mampu meraih nilai yang baik, lulus dalam semua mata kuliah, dan tentu saja berhasil menamatkan pendidikannya.

Jika ditinjau lebih jauh, kemampuan mahasiswa untuk menyesuaikan diri dengan lingkungan kampus atau college adjustment, juga dipengaruhi oleh salah satu aspek penting yang turut membantu keberhasilan mahasiswa di lingkungan perkuliahan. Mazaheri, Fatehizadeh, dan Asemi (2011), menyatakan bahwa aspek utama yang membantu meningkatkan kemampuan mahasiswa untuk 
menyesuaikan diri ialah peningkatan selfesteem. Penelitian dari Salami (2011) menunjukkan bahwa self-esteem merupakan salah satu prediktor yang kuat dalam kaitannya dengan college adjustment. Artinya, jika seorang mahasiswa memiliki nilai self-esteem yang tinggi, maka dia akan semakin mampu melakukan penyesuaian diri di lingkungan kampus. Sementara jika seorang mahasiswa memiliki nilai self-esteem yang rendah, maka dia cenderung tidak mampu melakukan penyesuaian diri di lingkungan kampus.

Duffy dan Atwater (2002), menjelaskan self-esteem sebagai evaluasi personal individu mengenai dirinya sendiri dan termanifestasi dalam bentuk tingkat kepuasan akan dirinya. Ketika individu memandang kehidupan secara negatif, selalu merasa tertekan, putus asa atau tiada harapan, berpikir bahwa dirinya buruk dan tidak memiliki kualitas yang baik, sehingga selalu menyalahkan dirinya saat orang lain tidak ingin berteman dengannya, maka individu tersebut termasuk dalam kategori individu dengan self-esteem yang rendah (Cloutte, 2001), sementara individu dengan self-esteem yang tinggi akan memandang dunia secara positif, dunia sebagai tempat yang baik dan kondusif untuk hidup, menilai diri sebagai individu yang memiliki banyak potensi dan kreativitas untuk dikembangkan, sehingga dirinya selalu terstimulasi untuk melakukan perubahan dan perkembangan ke arah yang lebih baik (Cloutte, 2001).

Self-esteem yang tinggi merupakan aspek yang penting untuk dimiliki oleh mahasiswa, sehingga dapat membantunya untuk menyesuaikan diri di lingkungan kampus, mampu memperoleh prestasi akademis yang baik, dan dapat terhindar dari depresi dan kecemasan yang turut meningkatkan level distres psikologis. Sebagai upaya untuk membantu mahasiswa baru menyesuaikan diri di lingkungan kampus, pihak universitas tentu telah mencoba melakukan berbagai cara. Salah satu cara yang umum dilakukan ialah dengan mengadakan program yang menyasar pada pengenalan lingkungan kampus dan metode pembelajaran. Tujuan pengenalan lingkungan kampus dan metode pembelajaran tersebut tentu untuk memudahkan mahasiswa tahun pertama menyesuaikan diri dengan lingkungan dan sistem belajar di kampus.

Sebagai salah satu universitas terbaik di Indonesia versi The Times Higher Education Magazine QS (THE QS) (Kompas.com, 2012) Universitas Indonesia sendiri melaksanakan Program Kegiatan Awal Mahasiswa Baru yang kegiatannya berkaitan dengan semua komponen pendidikan dan pengenalan berbagai kegiatan kemahasiswaan (Universitas Indonesia, 2010). Kegiatan tersebut lebih dikenal dengan nama PSAU (Pengenalan Sistem Akademik Universitas), yang terdiri dari keterampilan belajar (learning skill), pengenalan metode pembelajaran Collaborative Learning (CL) dan Problem Based Learning (PBL), pengenalan komputer dan computer mediated learning, serta pengenalan metode information literacy (pencarian sumber bacaan/literatur). Tiap mahasiswa wajib mengikuti PSAU agar mereka siap mengikuti proses pembelajaran di Universitas Indonesia dan mengenal lebih dekat serta mengembangkan networking dengan teman-teman mahasiswa dari fakultas yang berbeda (Universitas Indonesia, 2010). 
Ketika mahasiswa sudah mengenal lingkungan perkuliahannya, diharapkan ia akan mampu melakukan penyesuaian diri dengan baik sepanjang proses perkuliahan, sehingga memperkecil kemungkinannya untuk putus studi sebelum pendidikannya tamat. Akan tetapi pada kenyataannya jumlah presentase mahasiswa yang gagal dalam masa transisi ini juga cukup besar. Di Universitas Indonesia sendiri presentase mahasiswa program sarjana tahun akademik 2003-2005 yang mengalami putus studi meningkat dengan pesat, dari 1,69\% menjadi 5,26\% (Universitas Indonesia, 2007). Berdasarkan data PPSI UI per Desember 2010 yang diterima pada bulan Maret 2011 (Maishella, 2011), jumlah mahasiswa Universitas Indonesia yang dikeluarkan dan mengundurkan diri di tahun pertamanya mencapai 259 orang. Bahkan, masalah adjustment to college world (ACW) atau penyesuaian diri terhadap lingkungan kampus sendiri tetap masuk ke dalam tiga ranah masalah yang dianggap sebagai masalah yang sering dihadapi mahasiswa, selain ranah social and recreational activities (SRA) dan personal psychological relations (PPR) (Utama, 2010).

Melalui penjelasan tersebut, peneliti menyimpulkan bahwa program-program yang telah dilakukan oleh pihak Universitas Indonesia cenderung tidak menyasar aspek terpenting yang dapat menunjang keberhasilan mahasiswa dalam menyesuaikan diri, yaitu global self-esteem atau yang biasa disebut dengan self-esteem saja. Fakta tersebut menjadi perhatian bagi peneliti untuk mencoba memberikan program intervensi peningkatan self-esteem bagi mahasiswa Universitas Indonesia, karena dengan self-esteem yang rendah tentu akan menambah peluang mereka untuk mengalami kegagalan dalam performa akademis, serta turut meningkatkan level distres psikologisnya.

Pada awalnya peneliti ingin menyasar pada mahasiswa Universitas Indonesia angkatan pertama untuk membantu mereka agar lebih mudah melakukan penyesuaian diri di lingkungan kampus, namun hasil diskusi dari penelitian Maishella (2011) menyatakan bahwa masalah-masalah yang terkait dengan adjustment to college world ternyata tetap dianggap sebagai masalah meskipun mahasiswa telah memasuki tahun kedua. Ditambahkan pula oleh Stallman (2010) yang menjelaskan bahwa mahasiswa selalu menghadapi berbagai stressor yang berbeda tiap tahunnya, terutama stressor yang berkaitan dengan tuntutan akademis. Mahasiswa harus selalu mampu melakukan penyesuaian diri terhadap tuntutan-tuntutan yang berbeda sejak awal ia masuk ke dunia perkuliahan, hingga akhirnya harus menamatkan pendidikannya. Oleh karena itu, mahasiswa diharapkan mampu melakukan penyesuaian diri terhadap berbagai tuntutan yang muncul di dunia perkuliahan, sehingga tetap membutuhkan self-esteem yang cenderung tinggi untuk membantunya menyesuaikan diri dalam rentang masa perkuliahan yang berlangsung (Salami, 2011). Peneliti pun akhirnya menyasar mahasiswa S1 Universitas Indonesia dari berbagai angkatan untuk menjadi responden penelitian ini.

Ketika mahasiswa memiliki selfesteem yang tinggi, maka ia akan lebih mudah mengaplikasikan satu strategi coping ketika menghadapi masalah, termasuk masalah penyesuaian diri di lingkungan kampus atau 
college adjustment (Rosenberg, Schooler, Schoenbach, \& Rosenberg, 1995). Selain itu, self-esteem yang cenderung tinggi juga akan membantu individu untuk mengatasi distres psikologis yang muncul dan mengurangi kecemasan, sehingga individu tersebut dapat tetap menjalankan fungsinya dengan baik walaupun sedang mengalami stres atau trauma (Baumeister Campbell, Krueger, \& Vohs, 2003). Oleh karena itu, program intervensi peningkatan self-esteem pada mahasiswa tentu sangat diperlukan.

$$
\text { Duffy dan Atwater (2002) }
$$

menambahkan bahwa self-esteem bukanlah sesuatu yang sudah ada sejak lahir dalam diri seseorang. Self-esteem justru merupakan sebuah potensi yang dapat ditingkatkan dan dikembangkan, tidak peduli jika individu harus memulainya dari level serendah apapun. Jika self-esteem yang terletak di dalam diri individu itu dapat dikembangkan, maka individu tersebut memiliki kekuatan untuk mengubahnya. Proses perubahan perilaku individu tentunya harus melalui sebuah proses pembelajaran atau learning. Jarvis (2012) menjelaskan proses pembelajaran atau learning sebagai proses perubahan permanen sebuah perilaku yang dapat diamati (observable behavior) melalui pengalaman langsung dengan lingkungan. Menurut Bloom (1975), sasaran belajar yang efektif dapat meliputi tiga elemen perilaku yang akan diubah, yaitu sasaran kognitif, sasaran afektif, dan sasaran psikomotor. Metode intervensi yang mencakup perubahan pada ketiga elemen tersebut ialah training atau pelatihan.

Pelatihan dapat didefinisikan sebagai sebuah proses untuk memperoleh pengetahuan, sikap, dan keterampilan sebagai hasil pengalaman seseorang sehingga menghasilkan terjadinya perubahan perilaku (Laird, 1985). Definisi serupa juga diberikan oleh Vaughn (2005) yang menjelaskan pelatihan sebagai serangkaian kegiatan kelompok yang direncanakan untuk membantu mengarahkan terjadinya perubahan tingkah laku anggota kelompok ke arah tingkah laku tertentu yang diharapkan. Tiga domain perilaku yang dikembangkan dalam suatu pelatihan (Bloom, 1975), yaitu: kognitif (berkaitan dengan perolehan, retensi, dan pengembangan pengetahuan), afektif (berkaitan dengan perubahan sikap dan internalisasinya), dan elemen psikomotor (berkaitan dengan perolehan keterampilan yang mengakibatkan perubahan perilaku).

$$
\text { Furjanic dan Trotman }
$$
menjelaskan bahwa intervensi dalam bentuk pelatihan memiliki beberapa keunggulan, antara lain menumbuhkan harapan, kebersamaan, memperoleh informasi berkaitan dengan gangguan psikologis dan cara mengatasinya, mendapatkan dukungan sosial, mengembangkan keterampilan sosial dan interpersonal, meniru perilaku yang berhasil, membangun kebersamaan dalam kelompok, dan sarana katarsis. Furjanic dan Trotman (2000) juga menyampaikan keunggulan yang lebih spesifik dari metode pelatihan, antara lain memberikan kesempatan bagi anggota kelompok untuk belajar mencontoh tingkah laku anggota lain (modeling), belajar menerapkan pengetahuan dari anggota lain ke dalam kehidupannya (vicarious learning), memberikan saran kepada anggota lain (guidance), dan memberikan informasi antara satu sama lain (edukasi). Berdasarkan keunggulan-keunggulan tersebut, maka 
masalah dalam penelitian ini akan berfokus pada bagaimana intervensi pelatihan membantu meningkatkan self-esteem mahasiswa Universitas Indonesia yang memiliki tingkat distres psikologis yang tinggi.

Hasil dari penelitian ini diharapkan mampu memberikan masukan kepada pihak rektorat terkait kebijakan yang akan dibuat yang berhubungan dengan kesehatan mental, serta masukan kepada BKM (Badan Konseling Mahasiswa) UI dalam penanganan masalahmasalah kesehatan mental mahasiswa UI. Selain itu, hasil penelitian ini juga dapat dijadikan data baseline untuk penelitian selanjutnya yang terkait dengan peningkatan kesehatan mental mahasiswa UI.

Berkaitan dengan latar belakang masalah yang telah dipaparkan, perumusan masalah yang diajukan dalam penelitian ini adalah apakah intervensi dengan metode pelatihan dapat meningkatkan self-esteem mahasiswa Universitas Indonesia dengan tingkat distres psikologis tinggi.

\section{METODE}

Partisipan Penelitian. Populasi penelitian adalah seluruh mahasiswa program S1 Universitas Indonesia dari 12 fakultas, yaitu fakultas kedokteran, kedokteran gigi, kesehatan masyarakat, ilmu keperawatan, matematika dan ilmu pengetahuan alam, teknik, ilmu komputer, psikologi, ekonomi, hukum, ilmu pengetahuan budaya, dan ilmu sosial dan politik.

Kriteria partisipan yang diperlukan dalam penelitian ini ialah:
1. Mahasiswa Universitas Indonesia program S1 (reguler / ekstensi / internasional).

2. Memiliki status kewarganegaraan sebagai Warga Negara Indonesia (WNI) dan mampu berbahasa Indonesia.

3. Memiliki distres psikologis yang tinggi (Skor HSCL-25 di atas 1.75).

4. Memiliki keluhan dalam penyesuaian akademis selama menjalani perkuliahan (Skor Mooney Problem Checklist dalam ranah adjustment to college world di atas 8).

5. Memiliki self-esteem yang rendah (skor Rosenberg's Self-Esteem Scale dibawah 29).

6. Bersedia mengikuti intervensi yang dilakukan peneliti secara berkelompok dalam bentuk pelatihan selama 2 hari (@ \pm 6 jam) dengan mengisi informed consent yang disediakan oleh peneliti.

Desain Penelitian. Penelitian ini merupakan penelitian quasi eksperimental dengan desain satu kelompok disertai dengan pre dan posttest atau disebut juga desain before-after within subject (Kumar, 1999). Penelitian quasi eksperimental merupakan penelitian eksperimental dimana satu atau lebih syarat penelitian eksperimental tidak terpenuhi (Kerlinger \& Lee, 2000). Pada penelitian ini, syarat penelitian eksperimental yang terpenuhi adalah adanya manipulasi, yaitu pemberian intervensi terhadap responden, namun syarat yang tidak terpenuhi ialah tidak adanya kelompok kontrol dan randomisasi yang merupakan syarat penelitian eksperimental. 
Prosedur Penelitian. Screening dilakukan dengan memberikan tiga buah alat tes, yaitu HSCL-25 untuk mengukur distres psikologis, Mooney Problem Checklist untuk melihat ranah keluhan yang tampil, dan Rosenberg Self-Esteem Scale (RSES) untuk melihat tingkat self-esteem calon responden. Selain itu, peneliti juga melakukan wawancara terhadap calon partisipan untuk melihat riwayat keluhan dan latar belakang munculnya keluhan tersebut. Setelah peneliti memperoleh hasil screening, peneliti kemudian mengajak masing-masing partisipan terpilih untuk bertemu secara individual dan menjelaskan mengenai tujuan diadakannya intervensi serta gambaran kegiatan yang akan dilakukan.

Partisipan terpilih sebanyak 8 mahasiswa S1 Universitas Indonesia kemudian mengikuti pelatihan peningkatan self-esteem selama dua hari yang terdiri dari lima sesi utama (sekitar 6 jam dalam sehari). Peneliti yang juga bertindak sebagai pemandu mengembangkan modul pelatihan yang disesuaikan dari beberapa modul pelatihan peningkatan self-esteem seperti "Improving Self-Esteem" (Lim, Saulsman, \& Nathan, 2005) dan "Counselling Training Manual: Trauma, Guilt, \& Self-Esteem" yang diterbitkan oleh International Planned Parenthood Federation (No Name, 2009). Pada praktiknya, modul-modul tersebut membutuhkan waktu lebih dari dua hari dalam pelaksanaannya. Akan tetapi, peneliti mempertimbangkan komitmen dari partisipan dan efektivitas materi yang diperoleh, sehingga total waktu pelaksanaan menjadi dua hari.

Selain itu, apabila mengacu pada karakteristik individu dengan self-esteem yang tinggi menurut Rosenberg dkk. (1995), partisipan harapannya mampu mengidentifikasi potensi dalam diri, identifikasi kelemahan dan mengelolalnya menjadi sesuatu yang bermanfaat, mampu menghargai diri ada adanya dengan segala kelebihan dan kekurangan, berpikir positif terhadap diri, dan mampu mengembangkan diri. Oleh karena itu, kelima karakteristik tersebut dijadikan sasaran yang terangkum dalam dua hari (@6 jam)sesi pelatihan.

Pelatihan yang berjudul: "Self-Esteem Building Training: Higher Self-Esteem; Better Quality of Life" ini terdiri dari sesi:

1. "I am PROUD and OK!" $\rightarrow$ pada sesi ini pemandu seolah membagi ruangan menjadi dua bagian menggunakan lakban hitam, kemudian pemandu membacakan berbagai pernyataan yang sangat sederhana dan merupakan hal membanggakan tetapi cenderung dilupakan oleh partisipan. Jika partisipan memang pernah mengalami pernyataan tersebut, maka diijinkan melangkah menuju lakban hitam.

2. "I am good potentially" $\rightarrow$ pada sesi ini pemandu membagikan lembar kerja dimana partisipan harus menuliskan berbagai pengalaman positif yang pernah dialami hingga berjumlah 20, lalu mempresentasikan hasilnya di akhir.

3. "FRUITFUL" $\rightarrow$ pada sesi ini pemandu membagikan lembar kerja dan mengajak partisipan untuk menuliskan dan menggambarkan satu buah-buahan yang mewakili karakteristik partisipan. Partisipan juga diminta untuk menuliskan alasan 
dari pemilihan buah tersebut, baik kelebihan maupun kekurangan dari buah yang dipilih.

4. "Case Study" $\rightarrow$ pada sesi ini pemandu membagi peserta menjadi tiga kelompok dan membagikan lembar studi kasus. Kasus mengenai pencapaian dan kegagalan tokoh disusun sedemikian rupa agar partisipan dapat mengidentifikasi kekuatan dan kelemahan dari tokoh dalam kasus, serta faktor-faktor lain yang mungkin turut mempengaruhi pencapaian tokoh.

5. "Commercial Break" $\rightarrow$ pada sesi ini partisipan diajak untuk membuat proyek sebuah iklan tentang diri sendiri menggunakan media yang sederhana. Tiap partisipan harus menunjukkan aspek-aspek positif dari diri mereka melalui gambar, kata-kata, atau kombinasi keduanya sama seperti iklan yang biasanya memang menunjukkan aspek positif agar konsumen mau membeli produknya.

Pelatihan yang dilakukan mengikuti prinsip The Lewinian Experiential Learning Model (Kolb, 1984), dimana tiap sesi pelatihan harus mencakup pengalaman nyata yang dapat diobservasi dan diaplikasikan oleh peserta pelatihan (Concrete Experience-CE), sehingga mereka mampu melakukan evaluasi atau refleksi terhadap diri sendiri melalui pengalaman tersebut (Reflections $\boldsymbol{\&}$ Observations-RO), untuk kemudian membentuk satu perubahan kognisi, afeksi, dan psikomotor berkaitan dengan perubahan perilaku yang diharapkan dari pelatihan
(Abstract Conceptualization-AC), dan pada akhirnya mampu menguji implikasi perilaku baru tersebut pada situasi yang berbeda (Active Experimentation-AE). Jika digambarkan dalam bentuk skema, maka akan tampak seperti gambar berikut ini:

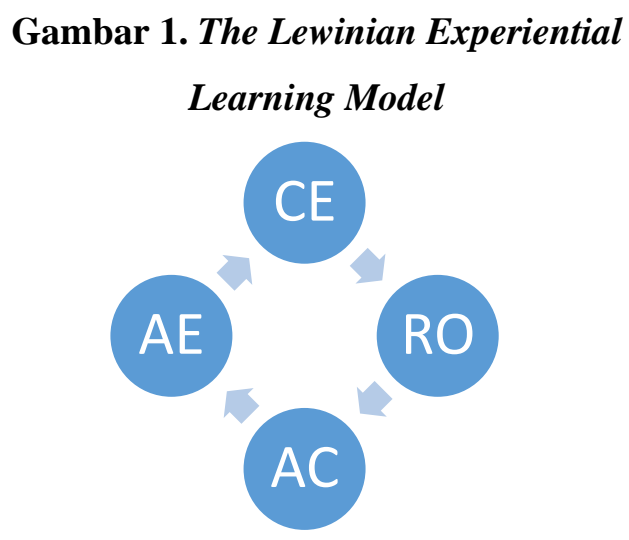

Prinsip tersebut diisi oleh kegiatan dengan berbagai metode seperti diskusi kelompok, permainan, studi kasus, simulasi, dan ceramah (Agochiya, 2002). Selain kegiatan yang terkait dengan judul pelatihan, pemandu juga menyisipkan kegiatan permainan sebagai ice breaker atau energizer pada awal sesi dan setelah waktu istirahat agar suasana pelatihan menjadi lebih kondusif, menyenangkan, dan tidak membosankan.

$$
\text { Pada akhirnya, peneliti }
$$

membandingkan data baseline dan data sesudah intervensi (pre-post test) dengan menggunakan alat ukur yang sama saat proses screening, dan melakukan uji non parametric dengan Wilcoxon Test untuk melihat signifikansi perubahan partisipan (Gravetter \& Wallnau, 2010).

Instrumen Penelitian. Penelitian ini menggunakan tiga alat ukur, yaitu kuesioner Hopkins Symptom Checklist-25 (HSCL-25), kuesioner Mooney Problem Checklist, dan 
kuesioner Rosenberg Self-Esteem Scale (RSES).

Kuesioner Hopkins Symptom

Checklist-25 yang digunakan berbentuk paper and pencil test dengan metode self-report berisi 25 pertanyaan mengenai kemunculan serta intensitas gejala kecemasan dan depresi yang dirasakan individu selama satu minggu terakhir (Sandanger, dkk, 1999). HSCL-25 memiliki konsistensi internal Cronbach's Alpha senilai 0.93, sehingga dapat dikatakan bahwa alat tes ini konsisten dalam mengukur tingkat distres psikologis (Kaaya, dkk., 2002).

Alat ukur ini mengunakan rating 4 poin untuk menentukan tingkat gangguan yang dirasakan individu, dari skala "1" yang berarti gejala tersebut tidak mengganggu sama sekali, hingga skala "4" yang berarti sangat mengganggu (Kaaya, dkk., 2002). Metode skoring alat ukur ini adalah dengan menjumlahkan skor dari tiap item, kemudian dibagi dengan jumlah item keseluruhan. Jika skor bernilai $\geq 1.75$, maka dapat dikatakan bahwa individu tersebut mengalami gangguan terhadap kesehatan mental atau memiliki level distres psikologis yang cenderung tinggi (Sandanger, dkk., 1999). HSCL-25 yang digunakan dalam penelitian ini merupakan hasil adaptasi ke bahasa Indonesia.

Kuesioner Mooney Problem Checklist digunakan untuk mensensus masalah apa saja yang dihadapi oleh individu. Alat ini berisi kumpulan masalah yang biasa dihadapi oleh para siswa, baik itu siswa Sekolah Menengah Pertama (SMP), Sekolah Menengah Atas (SMA), dan mahasiswa (Mooney \& Gordon, 1978). Para siswa harus membaca setiap item yang ada kemudian mereka dapat memberi respon dengan menggarisbawahi atau melingkari pernyataan yang merepresentasikan keluhan mereka. Masalah yang dilingkari adalah masalah yang menjadi fokus perhatian mereka (Mooney \& Gordon, 1978).

Kuesioner Rosenberg Self-Esteem Scale, mengukur self-esteem secara global, berfokus kepada penilaian seseorang terhadap dirinya sendiri, tanpa merujuk pada suatu kualitas atau atribut yang spesifik (Brown, 1998). Alat ukur ini berbentuk paper and pencil test dengan metode self--report, yang terdiri atas 10 item dan menggunakan rating 4 poin, dari skala "1" yang berarti subyek sangat tidak setuju dengan pernyataan yang diberikan, hingga skala "4" yang berarti subyek sangat setuju dengan pernyataan yang diberikan (Brown, 1998).

Metode skoring alat ukur ini adalah dengan menjumlahkan skor dari tiap item dengan rentang nilai total skor 10-40. Semakin tinggi skor pengerjaan, semakin tinggi juga harga diri individu (Brown, 1998). Pemberian skor alat tes ini adalah sebagai berikut:

Tabel 1. Skoring Rosenberg Self-esteem

Scale

\begin{tabular}{ll}
\hline Item & \multicolumn{1}{c}{ Skoring } \\
\hline & Sangat setuju $=4$ \\
& Setuju $=3$ \\
& Tidak setuju $=2$ \\
& Sangat tidak setuju $=1$ \\
& Sangat setuju $=1$ \\
& Setuju $=2$ \\
$3,5,8,9,10$ & Tidak setuju $=3$ \\
& Sangat tidak setuju $=4$
\end{tabular}

Alat tes ini telah diadaptasi dalam bahasa Indonesia dengan diujicobakan kepada 45 siswa SMP di Jakarta. Uji reliabilitas 
terhadap alat tes ini menunjukkan $\alpha=0.706$ (Della, 2010). Hasil uji validitas alat tes dengan menggunakan inter-item validity menunjukkan bahwa 9 dari 10 item valid dalam mengukur self-esteem. Satu item yang dinilai tidak valid adalah item nomor 8 dengan $r=0.236$ (Della, 2010).

Peneliti kemudian melakukan uji keterbacaan terhadap 18 mahasiswa Universitas Indonesia. Hasil uji keterbacaan menunjukkan bahwa secara umum penulisan kalimat dapat dipahami. Berdasarkan hasil uji reliabilitas, validitas, dan uji keterbacaan, peneliti melakukan perubahan item pada beberapa nomor antara lain:

Tabel 2. Daftar Perbaikan Item Rosenberg Self-esteem Scale

\begin{tabular}{lll}
\hline Item & Item Lama & Item Baru \\
\hline \multirow{3}{*}{1} & $\begin{array}{l}\text { Saya rasa saya } \\
\text { berharga, sama }\end{array}$ & Saya merasa \\
& halnya dengan & halnya dengan \\
& orang-orang lain & orang-orang lain \\
& Saya mampu & \\
& melakukan hal- & Saya mampu \\
4 & hal sebaik orang- & melakukan hal-hal \\
& orang lain & sebaik orang lain \\
& Ada saat dimana & Ada saat dimana \\
& saya merasa & saya merasa \\
& bahwa saya & bahwa diri saya \\
& buruk & buruk
\end{tabular}

Secara umum, norma untuk membedakan individu dengan self-esteem rendah dan tinggi di Indonesia menggunakan cut-off pada skor 30. Norma ini didasarkan pada penelitian Schmitt dan Allik (2005) terhadap 104 orang Indonesia yang menghasilkan $\mu=29.88$ dengan menggunakan Rosenberg's Self-Esteem Scale. Sementara itu, sebuah penelitian pada 153 mahasiswa berkebangsaan Iran di beberapa perguruan tinggi di Malaysia menunjukkan $\mu=28.81$ (Naderi, Abdullah, Aizan, Sharir, \& Kumar, 2009). Berdasarkan dua penelitian tersebut, peneliti memutuskan untuk menggunakan cutoff pada skor 29 sehingga responden yang memperoleh skor $\geq 29$ tidak akan diikutsertakan dalam penelitian karena memiliki self-esteem yang lebih tinggi dari rata-rata atau disimpulkan memiliki selfesteem yang cenderung tinggi.

Teknik Analisis. Data hasil intervensi akan dianalisis secara kuantitatif dan kualitatif. Secara kuantitiatif, peneliti akan membandingkan data baseline dan data sesudah intervensi setiap responden dengan menggunakan HSCL-25 dan Rosenberg SelfEsteem Scale. Kedua alat ukur ini akan diberikan sebanyak dua kali, yaitu saat screening dilakukan dan empat minggu setelah hari pertama pelatihan dilaksanakan. Kriteria efektivitas intervensi ini secara kuantitatif dilakukan dengan melihat perubahan skor rata-rata (mean) pada kedua alat tes tersebut dan uji signifikansi non parametric dengan Wilcoxon Test. Secara kualitatif, efektivitas intervensi ini akan dilihat dengan melalui teknik wawancara pada tiap responden.

\section{HASIL}

\section{Analisis Pre-Post Intervensi Pelatihan.}

Berdasarkan hasil pengukuran menggunakan "Inventori Gambaran Diri" sebelum dan sesudah pelatihan, seluruh responden mengalami perubahan skor self-esteem dan level distres psikologis. Berikut ini akan disajikan grafik perbandingan hasil skor 
Rosenberg Self-Esteem Scale dan HSCL-25 diberikan intervensi pelatihan.

seluruh responden, sebelum dan sesudah

\section{Gambar 2. Hasil Pengukuran Self-Esteem Pre-Post Pelatihan}

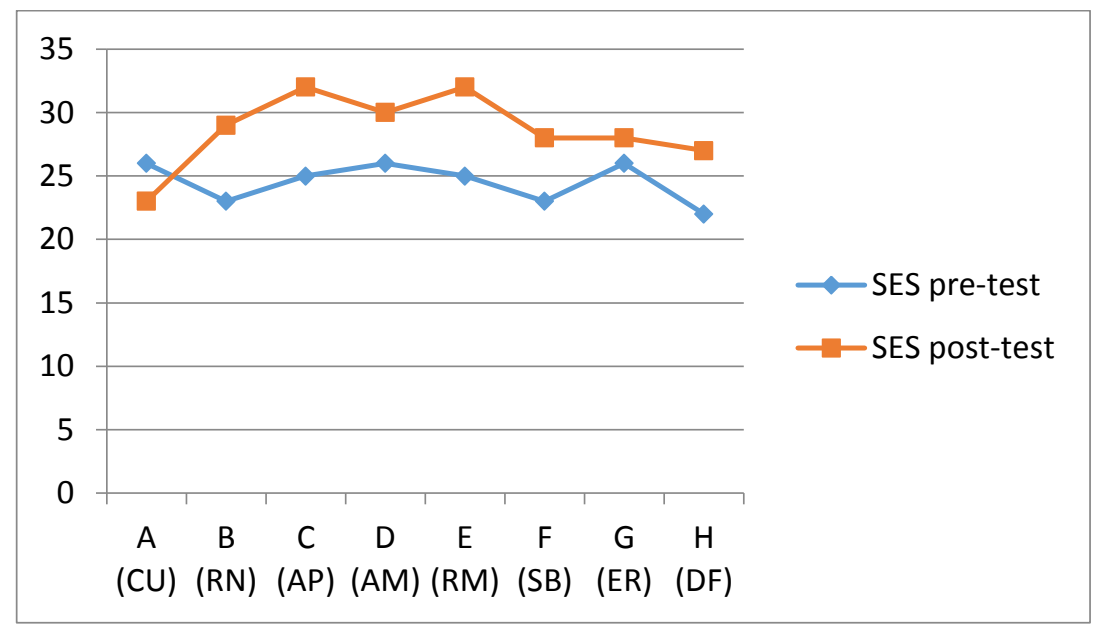

Jika dilihat melalui grafik di atas, satu responden mengalami penurunan selfsecara umum dapat disimpulkan bahwa esteem $(\mathrm{CU})$, namun penurunan tersebut hanya intervensi pelatihan dinilai berhasil sebesar 3 poin dari skor awal. meningkatkan self-esteem responden. Salah

\section{Gambar 3. Hasil Pengukuran Distres Psikologis Pre-Post Pelatihan}

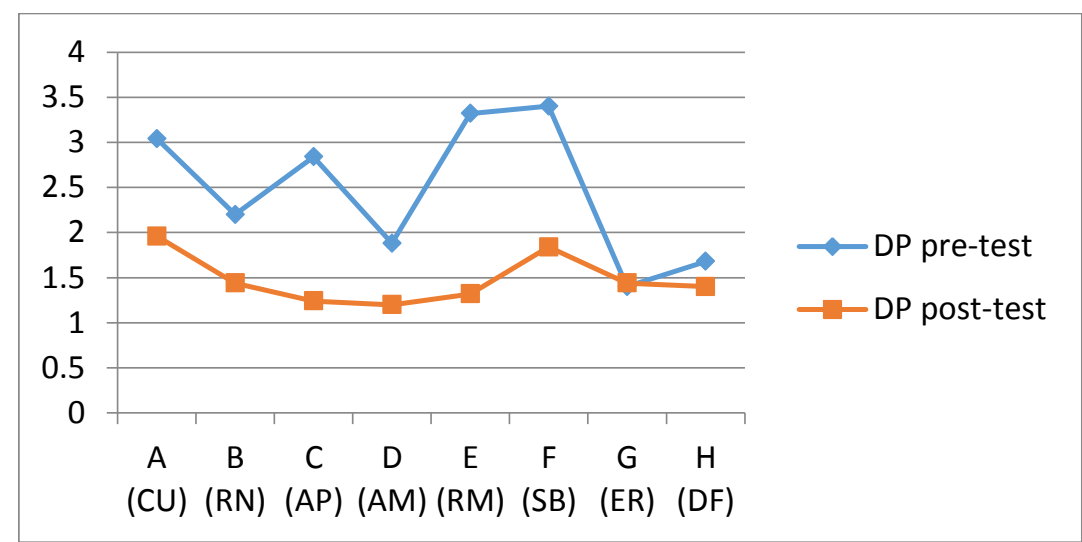

Berdasarkan grafik di atas, dapat disimpulkan pelatihan peningkatan self-esteem ini dinilai berhasil menurunkan level distres psikologis responden. Bahkan beberapa responden seperti AP, RM, dan SB mengalami penurunan level distres psikologis yang cukup drastis. Salah satu responden (ER) mengalami peningkatan level distres psikologis, namun peningkatannya hanya sebesar 0.04 poin dari skor awal.
Selain melihat perbedaan skor partisipan, peneliti juga melihat perbandingan skor rata-rata (mean) antara pre dan posttest, serta uji signifikansi non parametric dengan Wilcoxon Test.

Tabel 3. Tabel Deksriptif Self-Esteem

\begin{tabular}{ccc}
\hline Variabel & Mean & SD \\
\hline Self-Esteem pre & 24.50 & 1.60 \\
\hline Self-Esteem post & 28.62 & 2.92
\end{tabular}


Berdasarkan tabel di atas, skor ratarata (mean) RSES peserta pelatihan mengalami peningkatan antara pre dan post test, dimana M RSES pre $(\mathrm{SD})=24.50(\mathrm{SD}=$ 1.60) dan M RSES post $(\mathrm{SD})=28.62(\mathrm{SD}=$ 2.92). Dengan kata lain, intervensi pelatihan ini berhasil meningkatkan skala self-esteem peserta.

Selain itu, skor rata-rata HSCL-25 juga mengalami penurunan antara pre dan post test, dimana M HSCL pre $(\mathrm{SD})=2.47(\mathrm{SD}=$ $0.78)$ dan M HSCL post $(\mathrm{SD})=1.48(\mathrm{SD}=$ 0.28). Dengan kata lain, pelatihan peningkatan self-esteem ini turut menurunkan tingkat distres psikologis peserta. Hasil selengkapnya dapat dilihat pada tabel berikut ini.

Tabel 4. Tabel Deskriptif Distres Psikologis

\begin{tabular}{ccc}
\hline Variabel & Mean & SD \\
\hline Distres Psikologis pre & 2.47 & 0.78 \\
\hline Distres Psikologis post & 1.48 & 0.28
\end{tabular}

Peneliti juga melakukan uji signifikasi non parametric dengan Wilcoxon Test untuk mencari tahu apakah perubahan skor partisipan pada tiap variabel merupakan perubahan yang signifikan atau tidak. Hasil uji Wilcoxon pada skor pre dan post test $\mathrm{RSES}$ menunjukkan $\mathrm{Z}=$ -2.246, $\mathrm{p}<.05$. Sementara itu, hasil uji Wilcoxon pada skor pre dan post test HSCL25 menunjukkan $\mathrm{Z}=-2.366, \mathrm{p}<.05$. Hasil tersebut menunjukkan bahwa intervensi pelatihan peningkatan self-esteem ini memberikan perubahan yang signifikan pada peningkatan tingkat self-esteem dan penurunan level distress psikologis. Berikut ini dapat dilihat tabel uji Wilcoxon tiap variabel.
Tabel 5. Tabel Uji Statistik Wilcoxon

\begin{tabular}{ccc}
\hline Variabel & $\mathbf{Z}$ & Sign. \\
\hline RSES & -2.246 & .025 \\
\hline HSCL-25 & -2.366 & .018 \\
\hline
\end{tabular}

\section{SIMPULAN}

Intervensi pelatihan dinilai berhasil meningkatkan self-esteem dan menurunkan level distres psikologis mahasiswa Universitas Indonesia. Secara kuantitatif, tujuh dari delapan responden mengalami peningkatan self-esteem dan penurunan distres psikologis. Berdasarkan hasil uji signifikansi non parametric dengan Wilcoxon Test juga menunjukkan perubahan yang signifikan pada kedua variabel. Secara kualitatif, seluruh responden merasakan adanya manfaat dari intervensi pelatihan yang dapat mereka aplikasikan dalam kehidupan sehari-hari. Mereka memperoleh pengetahuan dan keterampilan baru mengenai peningkatan selfesteem. Meskipun beberapa responden masih belum merasakan adanya perubahan secara signifikan, namun motivasi dari dalam diri untuk terus melakukan penilaian diri secara positif dan dukungan dari lingkungan akan lebih membantu meningkatkan self-esteem responden di kemudian hari.

\section{DISKUSI}

Setelah peneliti memberikan intervensi pelatihan pada delapan mahasiswa Universitas Indonesia, secara umum hasil yang diperoleh ialah terjadinya peningkatan selfesteem dan penurunan level distres psikologis. Meskipun terdapat satu responden (CU) yang mengalami penurunan self-esteem dan satu responden (ER) justru mengalami peningkatan 
level distres psikologis, namun hal tersebut tidak menjadi indikasi kegagalan intervensi ini karena perubahan yang terjadi tidak terlalu signifikan. Selain itu, analisis pre-post intervensi secara kualitatif juga menunjukkan bahwa seluruh responden merasakan adanya peningkatan dalam hal self-esteem.

Berdasarkan hasil yang diperoleh, tentu terdapat beberapa hal yang dapat didiskusikan, salah satunya terkait dengan faktor yang mendukung perubahan perilaku masing-masing individu. Velicer, Prochaska, Fava, Norman, dan Redding (1998), menjelaskan bahwa perubahan perilaku individu terdiri dari lima tahapan (Stages of Change), yaitu: precontemplation, contemplation, preparation, action, dan maintenance. Tahap precontemplation merupakan tahap dimana individu belum memiliki niat untuk berubah. Tahap contemplation merupakan tahap dimana individu memiliki niat untuk berubah. Mereka lebih menyadari adanya pro dan kontra dari perubahan perilaku, sehingga akan mengarahkan mereka pada usaha untuk mengubah perilaku secara total atau justru tidak mengubahnya sama sekali. Tahap preparation ialah tahap dimana individu berusaha untuk mengambil tindakan yang mengarahkan mereka pada perubahan perilaku, misalnya berkonsultasi dengan konselor atau psikolog, berbicara dengan ahli kesehatan, membeli buku-buku self-help, dan lain-lain. Tahap action merupakan tahap dimana individu sudah membuat modifikasi gaya hidup secara tampak dan spesifik yang mencerminkan sebuah perubahan perilaku. Tahap maintenance ialah tahap dimana individu berusaha untuk mencegah dirinya kembali relapse ke perilaku yang lama.

Dalam penelitian ini, seluruh responden pada awalnya mengajukan diri setelah mengetahui informasi mengenai sesi konsultasi gratis melalui flyer, status di facebook dan twitter, dan media lainnya.

Mereka merasa sedang memiliki masalah dan ingin mengubah perilaku tertentu agar memperoleh kesejahteraan psikologis yang lebih baik. Jika dikaitkan dengan teori Stages of Change yang dikemukakan oleh Velicer, dkk. (1998), seluruh responden pada awalnya sudah berada pada tahap preparation, dimana mereka berusaha untuk mengambil tindakan yang mengarahkan mereka pada perubahan perilaku dengan berkonsultasi pada peneliti sebagai konselor. Hal ini tentu juga menunjukkan motivasi internal responden untuk berubah. Motivasi ini tampak dari kesediaan responden untuk bekerja sama memilih waktu pelatihan, memberi kabar pada peneliti jika ada halangan atau hambatan, datang tepat waktu saat pelatihan berlangsung, dan bersikap aktif dalam tiap sesi. Seorang terapis tentu akan lebih mudah memberikan intervensi pada seorang klien yang sudah berada pada tahap preparation, karena langkah selanjutnya ialah mengarahkan klien pada perubahan perilaku di tahap action, lalu mempertahankan perilaku baru tersebut di tahap maintenance.

Intervensi pelatihan yang diberikan merupakan sarana bagi seluruh responden untuk mengalami secara nyata perilaku yang diharapkan muncul pada individu dengan selfesteem yang tinggi, sehingga mereka dapat memenuhi tahap action dari perubahan perilaku. Setelah intervensi selesai diberikan, 
hasil wawancara pasca intervensi juga menunjukkan bahwa seluruh responden sedang berada dalam tahap mencoba perilaku baru pada beberapa situasi, dimana mereka membuat modifikasi gaya hidup secara tampak dan spesifik yang mencerminkan sebuah perubahan perilaku. Menurut mereka hal ini bukanlah hal yang mudah karena masih banyak faktor-faktor lain yang turut mendukung atau justru menghambat perubahan perilaku tersebut.

Beberapa literatur menjelaskan bahwa peningkatan atau penurunan self-esteem dapat dipengaruhi oleh berbagai faktor, antara lain: keluarga (Yatim \& Irwanto, 1986), kesuksesan dan kegagalan (Duffy \& Atwater, 2002), peer group (O’Donnel, 1976), kultur atau budaya tertentu (Mruk, 2006). Berdasarkan hasil wawancara setelah intervensi pelatihan diberikan, mayoritas responden merasa bahwa keluarga dan teman-teman mereka turut mempengaruhi naik atau turunnya self-esteem. Misalnya, ER yang masih sering mendengar ibunya kerap kali 'merendahkan' potensi yang ia miliki, atau AP yang merasa self-esteem-nya tidak meningkat dengan optimal karena orangtuanya cenderung masih merasa ragu akan kemampuan dirinya. Contoh lain yaitu: SB, RM, dan DF yang merasa keyakinan dalam diri mereka menjadi menurun akibat kegagalan untuk berkomitmen terhadap jadwal yang sudah mereka buat. Meskipun tingkat self-esteem mereka pada akhirnya meningkat, namun terdapat kemungkinan tingkat selfesteem mereka dapat meningkat lebih signifikan jika berada dalam lingkungan yang kondusif.

Meskipun pengaruh dari lingkungan begitu kuat mempengaruhi self-esteem individu, Mruk (2006) menjelaskan bahwa self-esteem tetap berkaitan dengan penilaian diri (self-evaluation) akan kompetensi dirinya pada bidang yang penting bagi individu tersebut. Oleh karena itu, ketika lingkungan memberikan penilaian negatif terhadap diri individu tetapi individu tersebut memiliki penilaian positif mengenai dirinya, terdapat kemungkinan self-esteem individu tersebut tetap akan tinggi. Hal ini dapat terlihat pada hasil wawancara seluruh responden yang mengatakan bahwa meskipun lingkungan kerap kali memberikan penilaian negatif pada diri mereka, namun materi self-esteem yang telah mereka peroleh selama sesi pelatihan memperkuat self-evaluation akan kompetensi pada bidang-bidang tertentu, sehingga membuat mereka lebih mampu untuk memberikan penilaian positif terhadap diri meski dalam taraf yang tidak terlalu signifikan. Masing-masing responden merasa penilaian positif terhadap diri mereka lebih ditujukan pada kompetensi ilmu yang mereka pelajari. Misalnya, mereka menjadi lebih yakin dalam menjawab soal-soal ujian atau kuis, merasa lebih percaya diri untuk melakukan presentasi, dan merasa lebih yakin dapat menyelesaikan kuliah dengan prestasi yang baik.

Setelah mengalami peningkatan selfesteem, level distres psikologis responden juga diharapkan menurun sebagai indikasi dari kemampuan mereka menghadapi dan menyelesaikan masalah perkuliahan dengan self-esteem yang lebih tinggi. Namun, hasil penurunan level distres psikologis yang variatif pada masing-masing responden juga tidak lepas dari faktor-faktor yang mempengaruhinya (Matthews, 2000), yaitu: 
faktor intrapersonal (trait kepribadian) dan faktor situasional (fisiologis, kognitif, sosial). Melalui hasil wawancara pasca intervensi dengan masing-masing responden, peneliti menyimpulkan perubahan level distres psikologis yang muncul lebih banyak dipengaruhi oleh faktor situasional kognitif dan sosial. Ketika responden memiliki selfesteem yang lebih tinggi, mereka lebih mampu menerima segala kelebihan dan kekurangan diri, menerima diri apa adanya, sehingga merasa yakin bahwa hambatan atau tantangan yang ada dalam hidup mereka bukan sematamata diakibatkan oleh kelemahan diri mereka saja. Intervensi pelatihan ini melatih responden untuk berpikir secara lebih divergen dan lebih positif dalam melihat masalah atau stressor. Selain itu, beberapa responden juga masih mengalami gangguan dalam hubungan sosial, seperti merasa belum nyaman bergaul dengan mahasiswa dari Jakarta karena berasal dari daerah, merasa tidak memperoleh dukungan dari orangtua karena masih diragukan, atau situasi seperti post-test intervensi yang dijadwalkan bersamaan dengan pekan UAS (Ujian Akhir Semester). Jika faktor-faktor tersebut dikontrol, terdapat kemungkinan level distres psikologis responden dapat menurun dengan lebih signifikan.

\section{DAFTAR PUSTAKA}

Abdullah, M. C., Elias, H., Mahyuddin, R., \& Uli, J. (2009). Adjustment amongst first year students in a Malaysian University. European Journal of Social Sciences, 8(3), 496-505.
Agochiya, D. (2002). Every Trainer's Handbook. New Delhi: Sage Publications India Pvt Ltd.

Arnett, J. J. (2000). Emerging adulthood: A theory of development from the late teens through the twenties. American Psychologist, 55(5), 469-480. doi: 10.1037/0003-066x.55.5.469

Baumeister, R. F., Campbell, J. D., Krueger, J. I., \& Vohs, K. D. (2003). Does high self-esteem cause better performance, interpersonal success, happiness, or healthier life style? Psychological Science in the Public Interest, 4(1), 144.

Bloom, B. S. (1975). Taxonomy of educational objectives. New York: David McKay Co, Inc.

Brown, J. D. (1998). The self. Boston: McGraw-Hill.

Cloutte, P. (2001). How to increase your selfesteem. Mental Health Promotion Series (booklet). London: Mind Publications.

Della. (2010). Hubungan antara harga diri, citra tubuh, dan kecemasan sosial pada remaja putri tingkat SMP di Jakarta (Skripsi tidak diterbitkan). Universitas Katolik Indonesia Atma Jaya, Jakarta.

DeRosier, M. E., PhD., Frank, E., PhD., Schwartz, V., M.D., \& Leary, K. A., PhD. (2013). The potential role of resilience education for preventing mental health problems for college students. Psychiatric Annals, 43(12), 538-544. doi:http://remotelib.ui.ac.id:2090/10.3928/00485713- 
Duffy, K. G., \& Atwater, E. (2002). Psychology for living: Adjustment, growth, and behavior today (7th Ed.). New Jersey: Pearson Education, Inc.

Furjanic, S. W. \& Trotman, L. A. (2000). Turning Training into Learning: How to Design and Deliver Programs That Get Results. USA: AMACOM.

Gravetter, F. J., \& Wallnau, L. B. (2010). Statistics for the Behavioral Sciences ( $9^{\text {th }}$ Ed.). USA: Cengage Learning.

Hales, D. (2009). An Invitation to Health (13 ${ }^{\text {th }}$ Ed.). Belmont, CA: Wadsworth/Cengage Learning.

Jarvis, P. (1987). Adult Learning in the Social Context. London: Routledge, https://doi.org/10.4324/978020380272 4

Kaaya, S. F., Fawzi, M.C., Mbwambo, J. K., Lee, B., Msamanga, G. I., Fawzi, W. (2002). Validity of the Hopkins Symptom Checklist-25 amongst HIVpositive pregnant women in Tanzania. UK: Blackwell Munksgaard.

Kerlinger, F. N., \& Lee, H. B. (2000). Foundations of behavioral research (4th Ed.). USA: Harcourt, Inc.

Kolb, D. A. (1984). Experiential Learning: Experience as the Source of Learning and Development. New Jersey: Prentice-Hall, Inc.

Kumar, R. (1999). Research methodology: A step by step guide for beginners. London: Sage Publications, Ltd.

Laird, D. (1985). Approaches to training and development (2nd Ed.). Massachusetts: Addison Wesley Publishing Company.

Lim, L., Saulsman, L., \& Nathan, P. (2005). Improving Self-Esteem. Perth, Western
Australia: Centre for Clinical Interventions.

Maishella, P. (2011). Masalah Adjustment to college work dan faktor prediktor psychological distress pada mahasiswa tahun kedua di Universitas Indonesia (Skripsi tidak dipublikasikan). Universitas Indonesia, Depok.

Matthews, G. (2000). Distress. In Fink (Ed.), Encyclopedia of stress (Vol. 1, pp AD). New York: Academic Press.

Mazaheri, A., Fatehizadeh, M., \& Asemi, A. (2011). Effect of behavioral-cognitive self-esteem group training on students' social adjustment. Interdisciplinary Journal of Contemporary Research in Business, 3(2), 202-209.

Mirowsky, J., \& Ross, C. E. (2003). Social cause of psychological distress. New York: Aldine de Gruyter.

Mooney, R. L., \& Gordon, L. V. (1978). Mooney problem check-list. United States of America: Harcout Brace Jovanovich, Inc.

Mruk, C. J. (2006). Self-Esteem research, theory, and practice: Toward a positive psychology of self-esteem (3rd Ed.). New York: Springer Publishing Company, Inc.

Naderi, H., Abdullah, R., Aizan, H. T., Sharir, J., \& Kumar, V. (2009). Self-esteem, gender and academic achievement of undergraduate students. American Journal of Scientific Research, 3, 2637.

Napitupulu, E. L. (2012, September 12). PTN Indonesia masuk Universitas top dunia. Kompas.com. Diunduh dari 
https://edukasi.kompas.com/read/2012 /09/12/1703257/PTN.Indonesia.Masuk .Universitas.Top.Dunia

No Name. (2009). Counselling Training Manual: Trauma, Guilt, \& SelfEsteem. New Delhi: International Planned Parenthood Federation.

O’Donnel, W. J. (1976). Adolescent selfesteem related to feelings toward parents and friends. Journal of Youth Adolescence, 5, 179-185.

Papalia, D. \& Martorell, G. (2014). Experience human development (13th ed.). New York, NY: McGraw-Hill.

Rosenberg, M., Schooler, C., Schoenbach, C., \& Rosenberg, F. (1995). Global selfesteem and specific self-esteem: Different concepts, different outcomes. American Sociological Review, 60(1), 141.

Salami, S. O. (2011). Psychosocial Predictors of Adjustment Among First Year College of Education Students. USChina Education Review, 8(2), 239248.

Saleh, D., Camart, N., dan Romo, L. (2017) Predictors of Stress in College Students. Frontiers in Psychology. 8(19). DOI:10.3389/fpsyg.2017.00019

Sandanger, I., Moum, T., Ingebrigtsen, G., Sorensen, T., Dalgard, O. S., \& Bruusgaard, D. (1999). the meaning and significance of caseness: The Hopkins Symptom Checklist-25 and The Composite International Diagnostic Interview II. Social Psychiatry and Psychiatric Epidemiology, 34, 53-59.
Santrock, J. W. (2013). Adolescence $\left(15^{\text {th }}\right.$ Ed.). New York: McGraw-Hill.

Stallman, H. M. (2010). Psychological distress in university students: A comparison with general population data. Australian Psychologist, 45(4), 249257.

DOI:10.1080/00050067.2010.482109

Universitas Indonesia. (2007). UI dalam angka. Diunduh dari http://www.ui.ac.id/download/ui_dala m_angka.pdf

Universitas Indonesia. (2010). Panduan Kegiatan Awal Mahasiswa Baru Universitas Indonesia Tahun Akademik 2010/2011. Depok: UI Press.

Utama, B. (2010). Kesehatan mental dan masalah-masalah pada mahasiswa S1 Universitas Indonesia (Skripsi tidak dipublikasikan). Universitas Indonesia, Depok.

Vaughn, R. H. (2005). The professional trainer. San Fransisco: BerrettKoehler Publisher, Inc.

Velicer, W. F., Prochaska, J. O., Fava, J. L., Norman, G. J., \& Redding, C. A. (1998). Smoking cessation and stress management: Applications of the transtheoretical model of behavior change. Homeostatis, 38, 216-233.

Verger, P., Combes, JB., Kovess-Masfety, V., Choquet, M., Guagliardo, V., Rouillon, F., \& Peretti-Wattel, P. (2009). Psychological distress in first year university students: socioeconomic and academic stressors, mastery and social support in young men and women. Social Psychiatry 
and Psychiatric Epidemiology, 44(8),

643-650.

https://doi.org/10.1007/s00127-008-

0486-y

Yatim, D. I., \& Irwanto. (1986). Kepribadian

keluarga dan narkotika: Tinjauan

sosial psikologis. Jakarta: Arcan. 